Network Working Group

Request for Comments: 2325

Category: Informational

M. Slavitch

Loran Technologies Inc.

1 April 1998

\title{
Definitions of Managed Objects for Drip-Type Heated Beverage Hardware Devices using SMIv2
}

Status of this Memo

This memo provides information for the Internet community. It does not specify an Internet standard of any kind. Distribution of this memo is unlimited.

Copyright Notice

Copyright (C) The Internet Society (1998). All Rights Reserved.

Table of Contents

1. Introduction $\ldots \ldots \ldots \ldots \ldots \ldots \ldots \ldots \ldots \ldots \ldots \ldots \ldots \ldots \ldots \ldots$

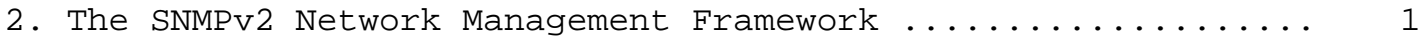

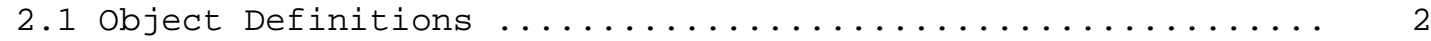

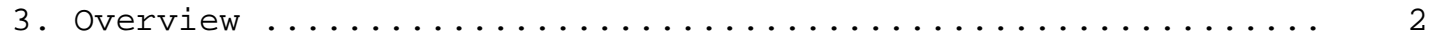

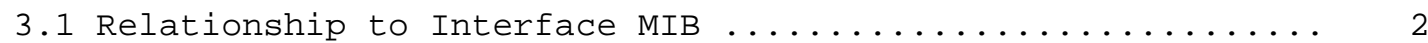

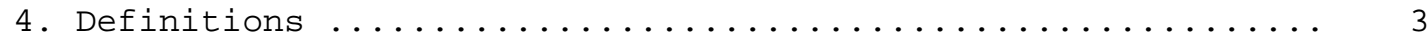

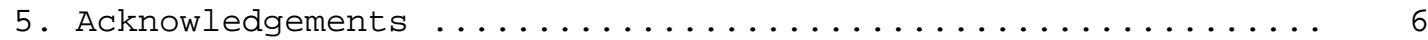

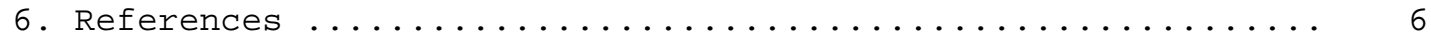

7. Security Considerations ..................... 6

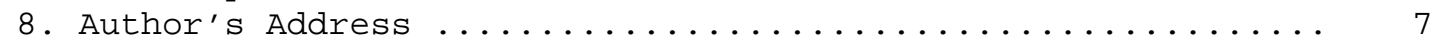

9. Full Copyright Statement ..................... 8

1. Introduction

This memo defines an extension to the Management Information Base (MIB) for use with network management protocols in the Internet community. In particular, it defines objects for the management of coffee-brewing and maintenance devices.

2. The SNMPv2 Network Management Framework

The SNMPv2 Network Management Framework consists of four major components. They are:

o RFC 1442 [1] which defines the SMI, the mechanisms used for describing and naming objects for the purpose of management. 
- STD 17, RFC 1213 [2] defines MIB-II, the core set of managed objects for the Internet suite of protocols.

o RFC 1445 [3] which defines the administrative and other architectural aspects of the framework.

o RFC 1448 [4] which defines the protocol used for network access to managed objects.

The Framework permits new objects to be defined for the purpose of experimentation and evaluation.

\subsection{Object Definitions}

Managed objects are accessed via a virtual information store, termed the Management Information Base or MIB. Objects in the MIB are defined using the subset of Abstract Syntax Notation One (ASN.1) defined in the SMI. In particular, each object object type is named by an OBJECT IDENTIFIER, an administratively assigned name. The object type together with an object instance serves to uniquely identify a specific instantiation of the object. For human convenience, we often use a textual string, termed the descriptor, to refer to the object type.

\section{Overview}

The COFFEE POT MIB applies to managed devices that brew, store, and deliver heated coffee beverages. The COFFEE POT MIB is mandatory for all systems that have such a hardware port supporting services managed through some other MIB.

The MIB contains objects that relate to physical connections, configuration, storage levels, availabilty, quality of service, and availability.

\subsection{Relationship to Interface MIB}

The COFFEE-POT-MIB is one of many MIBs designed for layered use as described in the Interface MIB [5]. In most implementations where it is present, it will be in the lowest interface sublayer, that is, the COFFEE-POT-MIB represents the physical layer, providing service to higher layers such as the character MIB [6].

Although it is unlikely that a coffee port will actually be used as a network interface, which is the intent of the Interface MIB, the COFFEE-POT-MIB is closely connected to the Character MIB, which can share hardware interfaces with network operation, and relate to the RS-232 MIB [7]. 
The Interface MIB's ifTestTable and ifRcvAddressTable are not relevant to the COFFEE-POT-MIB.

The COFFEE-POT-MIB is relevant for ifType values sip(31), and perhaps others.

The COFFEE-POT-MIB requires the conformance groups ifGeneralGroup, and iffixedLengthGroup.

Usefulness of error counters in this MIB depends on the octet counters in iffixedLengthGroup.

4. Definitions

COFFEE-POT-MIB DEFINITIONS : := BEGIN

IMPORTS

MODULE-IDENTITY, OBJECT-TYPE, NOTIFICATION-TYPE,

Timestamp, TimeInterval,

Counter32, Integer32 FROM SNMPv2-SMI

InterfaceIndex FROM IF-MIB

transmission FROM RFC1213-MIB

MODULE-COMPLIANCE, OBJECT-GROUP FROM SNMPV2-CONF;

Coffee MODULE-IDENTITY LAST-UPDATED "9803231700Z"

ORGANIZATION "Networked Appliance Management Working Group" CONTACT-INFO

Michael Slavitch

Loran Technologies, 955 Green Valley Crescent

Ottawa, Ontario Canada K2A OB6

Tel: 613-723-7505

Fax: 613-723-7209

E-mail: slavitcheloran.com"

DESCRIPTION

"The MIB Module for coffee vending devices." $::=\{$ transmission 132$\}$

potName OBJECT-TYPE

SYNTAX Displaystring (SIZE (0..255))

MAX-ACCESS read-only 


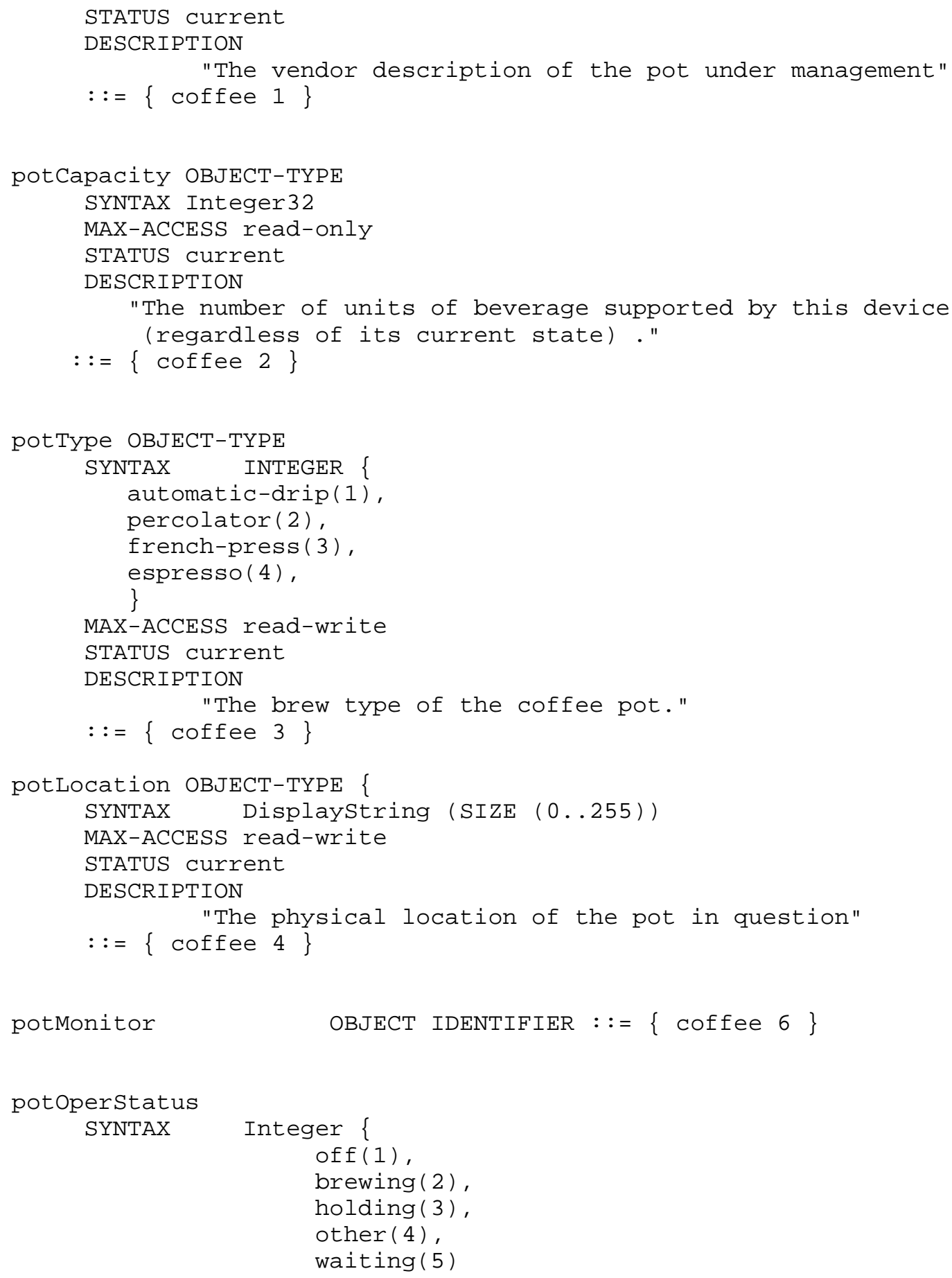




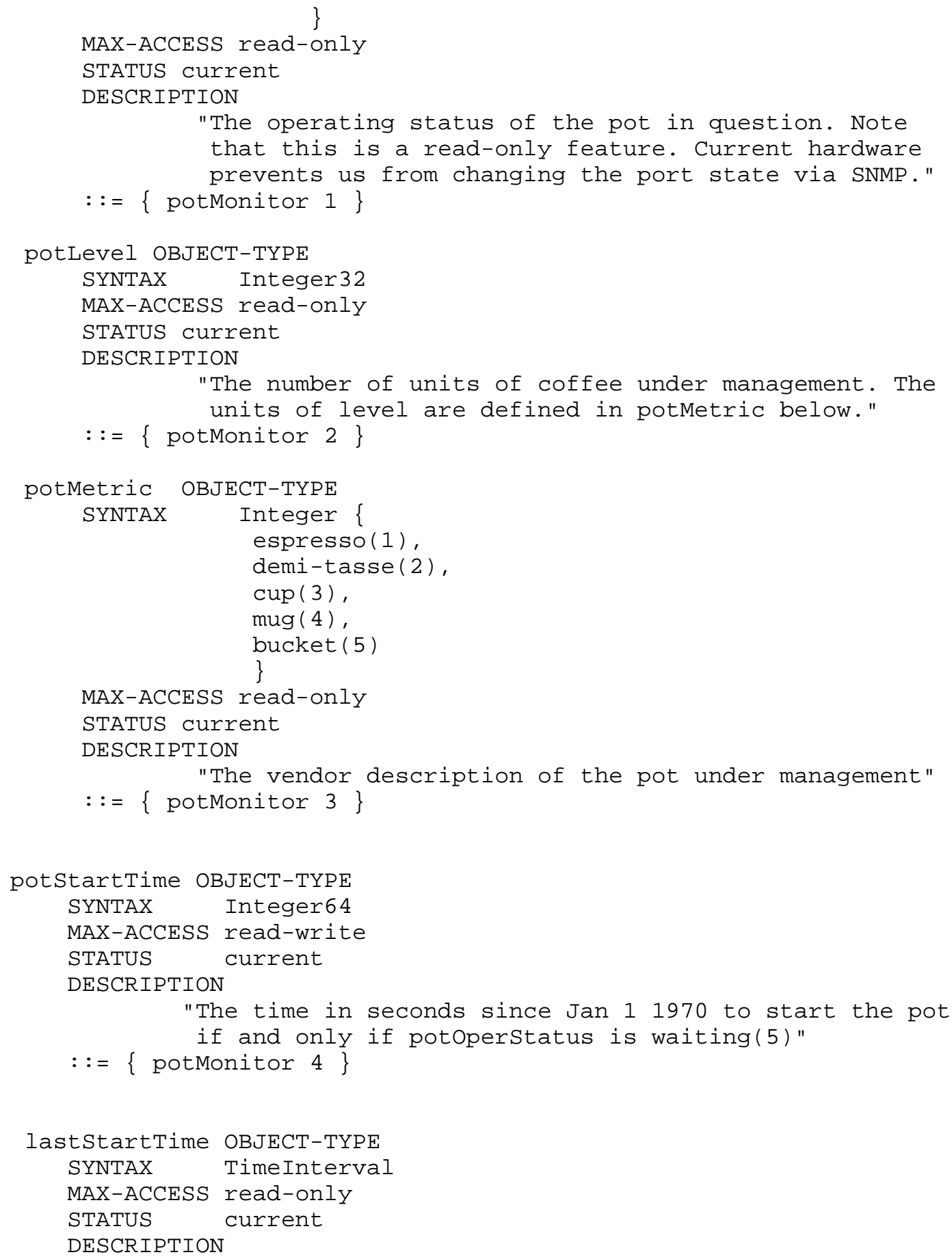




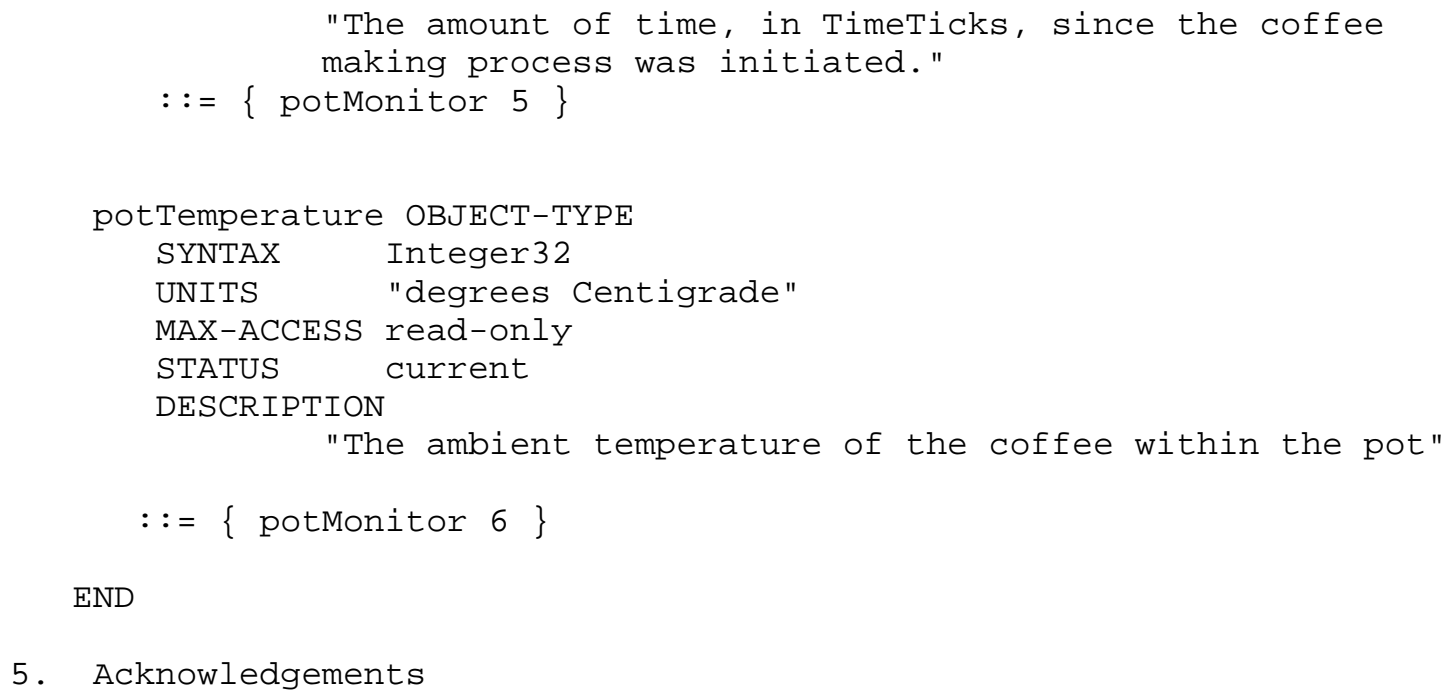

END

5. Acknowledgements

Networked Appliance Management Working Group (not) of the IETF.

6. References

[1] Case, J., McCloghrie, K., Rose, M., and S. Waldbusser, "Structure of Management Information for version 2 of the Simple Network Management Protocol (SNMPv2)", RFC 1442, April 1993.

[2] McCloghrie, K., and M. Rose, Editors, "Management Information Base for Network Management of TCP/IP-based internets: MIB-II", STD 17, RFC 1213, March 1991.

[3] Galvin, J., and K. McCloghrie, "Administrative Model for version 2 of the Simple Network Management Protocol (SNMPv2) ", RFC 1445, April 1993.

[4] Case, J., McCloghrie, K., Rose, M., and S. Waldbusser, "Protocol Operations for version 2 of the Simple Network Management Protocol (SNMPv2)", RFC 1448, April 1993.

[5] McCloghrie, K., and F. Kastenholz, "Evolution of the Interfaces Group of MIB-II", RFC 1573, January 1994.

[6] Valdez, Juan, "Definitions of Columbian Objects for Coffee Pot Devices using SMIv2", Columbia, Inc., March 1998.

7. Security Considerations

Security issues are not discussed in this memo. 
8. Author's Address

Michael Slavitch

Loran Technologies

955 Green Valley Crescent

Ottawa, Ontario Canada K2C 3V4

Phone: 6137237505

EMail: slavitcheloran.com 
9. Full Copyright statement

Copyright (C) The Internet Society (1998). All Rights Reserved.

This document and translations of it may be copied and furnished to others, and derivative works that comment on or otherwise explain it or assist in its implementation may be prepared, copied, published and distributed, in whole or in part, without restriction of any kind, provided that the above copyright notice and this paragraph are included on all such copies and derivative works. However, this document itself may not be modified in any way, such as by removing the copyright notice or references to the Internet society or other Internet organizations, except as needed for the purpose of developing Internet standards in which case the procedures for copyrights defined in the Internet Standards process must be followed, or as required to translate it into languages other than English.

The limited permissions granted above are perpetual and will not be revoked by the Internet society or its successors or assigns.

This document and the information contained herein is provided on an "AS IS" basis and THE INTERNET SOCIETY AND THE INTERNET ENGINEERING TASK FORCE DISCLAIMS ALL WARRANTIES, EXPRESS OR IMPLIED, INCLUDING BUT NOT LIMITED TO ANY WARRANTY THAT THE USE OF THE INFORMATION HEREIN WILL NOT INFRINGE ANY RIGHTS OR ANY IMPLIED WARRANTIES OF MERCHANTABILITY OR FITNESS FOR A PARTICULAR PURPOSE. 